CDU 015(81)(05)

\title{
A BIBLIOGRAFIA BRASILEIRA EM NOVA FASE
}

\author{
MYRNA BIER APPEL \\ Mestre em Literaturas de Lingua Portuguesa *
}

Estar informado sobre as novas publicações em sua área de atuação é um dehafio com que se defronta, em nossos dias, todo profissional para quem a leitura e o estudo constante são um imperativo.

Se a visita periódica às livrarias traz consigo o prazer de estar entre livros, fotheálos, examinar sumários, descobrir novidades e preciosidades antigas, além da boa conversa com o livreiro ou outros habituais freqüentadores da casa, ela não é, por certo, meio por si só suficiente para uma mais ampla atualização bibliográfica.

Em nosso País, temos algumas publicações cujo objetivo específico é justamente oferecer essa possibilidade, através de levantamentos bibliográficos periódi608 , acompanhando o movimento editorial. Infelizmente, também nesse campo, nos falta percorrer um longo caminho para alcançarmos o volume e a sofisticação desle tipo de informação tal como se encontra em países desenvolvidos. Mas é importante conhecer e divulgar o que já possuímos, pelas vantagens que decorrem da coniulta a essas publicações, para os profissionais ligados à área humanística, bem como a técnica e à científica.

Entre as fontes bibliográficas existentes no país, abordaremos neste momento Bibliografia Brasileira ${ }^{1}$, publicação oficial do Ministério da Educação e Cultura, lob a responsabilidade da Biblioteca Nacional, lançada em 1984 e referente ao 1 ? iemestre de 1983.

Considerando que a função precípua da Biblioteca Nacional é conservar para a posteridade o patrimônio bibliográfico da nação ${ }^{2}$, ali reunido por força do deposito legal (que obriga à remessa a ela de um exemplar de todas as obras publicadas no pars), é natural que lhe caiba também a produção da bibliografia nacional corrente.

E acidentada e pontilhada de interrupções a história da compilação da produção editorial entre nós. Desde a publicação do primeiro Boletim Bibliográfico da Biblioteca Nacional, em 1886, longos períodos houve em que nossa produção bi-

"Pofossora Assistente de Língua e Literatura Latina, Departamento de Letras Clássicas e Vernaeulas, Instituto de Letras, Universidade Federal do Rio Grande do Sul.

I BIBLIOGRAIIA BRASILEIRA, Rio de Janeiro, v.1, n.1/2, 1983..

IONSECA, Edson Nery da, Bibliografia Brasileira corrente: evolução e estado atual do problema. Crencia de Informaço, Rie de Janeiro, I(1):12, 1972. 
blográfica ficou a descoberto. Em determinadas épocas, o Instituto Nacional do Livio assumiu a tarefa descumprida pela Biblioteca Nacional; em outras, chegou a haver duplicação do trabalho pelas duas entidades ${ }^{3}$.

\section{Renovação da Biblioteca Nacional}

Inaugura-se com o presente volume uma nova e promissora fase. Acompanhando o sopro de renovação e vitalidade insuflado pela restauração física do prédio, iniciada na gestão de Célia Zaher e recentemente conclu ída, transformando o velho casaráo num dos mais belos e preciosos prédios públicos que possuímos, tamvêtmo funcionamento interno da instituiç̃ foi reformulado. Quem hoje visita nosbém o funcionamento interno da instituição foi reformulado. Quem hoje visita nosiii Biblioteca Nacional admira não só as obras de arte que a ornamentam e o acerto de todos os elementos decorativos, mas também o dinamismo e eficiência de seus de iervesos. Atualmente, oregistro das obras enviadas encont feita rapidamente; recursos çlo do ISBN (International Standard Book Number) é feita rapidamente; recursos letrônicos avançados convivem com obras raras; profissionais competentes e ateneiesos orientam os usuários.

Uma decisão inteligente preservou o trabalho já realizado, de maneira que os eatalogos para utilização dos leitores contêm desde antigas fichas manuscritas, às dailemafadas, até as produzidas por computador, oferecendo uma visão histórica da instituię̧̃o.

\section{A Automação dos serviços}

Introduzida a automação dos serviços, várias săo as vantagens decorrentes. Primeiramente, a rapidez do processamento das obras que, classificadas e catalogada por bibliotecários da $\mathrm{BN}$, têm seu registro efetuado e multiplicado em quantas fielas eatalográficas forem necessárias, num tempo mínimo, pela Fundação Getúlio tiehas eatalográficas forem necessárias, num toma Brasileira - é resultante do processo e Vargas. A própria publicação - Bibliografia Brasileira - é resultante do processo e
pode ser adquirida na forma tradicional impressa, mas também em fita magnética ou mierofichas.

Além disso, como explica na Apresentação a Diretora-Geral Maria Alice Bartolo, todas as obras arroladas nesta Bibliografia têm sua memória registrada em fi ial no Centro de Processamento de Dados da Fundação Getúlio Vargas. Isto possibilita levantamentos retrospectivos por autor, assunto e título.

Para uma informação mais detalhada do assunto ver CALDEIRA P. T. \& CARVALHO, M. L. 1. de. O problema editorial da bibliografia brasileira corrente. Revista Brasileira de Biblioteco namia e Documentação, São Paulo, 13(3/4): 210-6, jul./dez. 1980 e também o artigo mencionade na nota 2.
$\mathrm{Na}$ Introdução, Maria Célia da Matta, chefe da divisão de Processamento Técnico, fornece as informações técnicas necessarias: a obra será trimestral, arrolando todas as obras recebidas por depósito legal. Lista, portanto, autores nacionais e estrangeiros publicados no país. Acrescenta obra de autores nacionais editadas em outros países e adquiridas pela BN. O presente volume exclui periódicos, mapas, partituras, discos e material efêmero. Ainda : 'E uma bibliografia ordenada por assuntos, de acordo com a $19^{a}$. edição do Sistema de Classificação de Dewey (CDD), com os registros em forma de fichas catalográficas; as entradas e a descrição bibliográfica atendem as exigências da 2 a edição do Código de Catalogação Anglo-Americano (AACR2), e os cabeçalhos de assuntos obedecem a um vocabulário controlado, com base na Lista da Library of Congress. Indices de autores, títulos e assuntos remetem ao número de ordem do item catalogado."

\section{Manuseio da obra}

O manuseio da obra possibilita algumas observações. Após a Apresentação e a Introdução, que fornecem sucintamente o histórico, os objetivos e os princípios norteadores da obra, é estampada a Classificação Decimal de Dewey, nos itens mais gerais de suas dez classes (três dígitos, detalhando as dezenas), o que permite ao leitor a localização do assunto procurado através de número de classificação, que é o critério de ordenação da Bibliografia. Assim, caso o leitor queira saber o que se publicou na área de Estatística, durante o primeiro semestre de 1983 no país basta procurar na obra o número 310 . Na página 62 encontrará sob o título 310 ESTATISTICA (até 318) sete obras arrolàdas e descritas. Constam da descrição: nome do autor, título da obra, local, editora e data, formato, informações sobre número de páginas, ilu strações, bibliografia, coleção. Pistas para desdobramento de fichas catalográficas, muito úteis para o trabalho dos bibliotecários, servem aos outros profissionais como indicações sumárias sobre assuntos versados na obra. Ao final da ficha, à esquerda, o número de classificação mais detalhado; à direita, o número do item na ordem seqüencial da Bibliografia. Quando se trata da obra traduzida, o título original precede o da tradução. Nesta sistemática são arroladas 6.066 obras.

\section{Recursos adicionais}

Segue o Indice de Autores (p. 397-489), em ordem alfabética de sobrenomes, fornecendo, abaixo do nome do autor, o título de suas obras, com remissão ao número da obra na ordem seqüencial da Bibliografia. Autor, tradutor, organizador, etc. aparecem listados no mesmo tópico neste Índice. Assim, abaixo do nome "Quintana, Mário, 1906 -" arrolam-se títulos de obras em que o poeta é autor ( $A$ vaca e o hipogrifo, Poesias. Seleções) e aquelas em que figura como tradutor ( $O$ caminho de Guermantes, No caminho de Swann, etc.) ( $\mathrm{p} .467)$. 
O Indice de Titulos (p.493-548) estampa apenas o titulo da obra e seu número na Bibliografia.

O Indice de Assuntos (p. 551-633) traz, além do assunto principal, subdiviHōes que o especificam; autores, personagens históricas, artísticas, etc., nomes geopáficos, sempre que forem assuntos de obras, são igualmente listados.

As datas de nascimento e morte (se for o caso) dos autores citados encontram-se tanto na seção Bibliografia, como no Indice de autores.

Naturalmente esses índices sTo um valioso auxilio para o consulente, que đispōe de vários recursos para localizar os materiais que the interessam.

Uma relação de editoras do país, com endereço, etc. seria um acréscimo valioso à obra, sobretudo considerando o reduzido número de livrarias do país e até mesmo sua inexistência fora dos centros maiores: possibilitaria o contato direto do leitor com a editora, sempre que necessário.

E curioso notar que, embora o Boletim Bibliográfico da Biblioteca Nacional, de que a presente Bibliografia Brasileira é continuadora, tivesse adotado, já em 1918, a Classifcaçao Decimal Universal, sem dúvida mais flexível, hospitaleira e abrangente do que a CDD, tendo esta sido adotada posteriormente, num indício da predominancia da metodologia norte-americana que passou a se impor nos cursos de hiblioteconomia no país.

Impressa em Xerografia pela Editora José Olympio, a partir das listagens de computador, esta Bibliografia Brasileira é estampada em três colunas verticais, com a aipecto gráfico característico dos produtos da automação. Exige do leitor menos afeito a esse tipo de material uma atenção mais acurada, pois inexistem os recursos diveraificados de destaques conferidos por tipos variados nos sistemas tradicionais de eomposição gráfica.

\section{Perapectivas futuras}

O que se deseja a partir desta public ação renovada é que ela se atualize rapidimente, cobrindo o restante da produção bibliográfica de 1983 e a de 1984; que inelua, o quanto antes, os outros materiais até aqui excluídos; que venha a ter conlinuidade a fim de tornar-se, de fato, uma bibliografia corrente.

Se as gestőes futuras da Biblioteca Nacional derem continuidade a essa obra, Aẫo ineidindo no malfadado hábito de destruir ou desprezar as realizações de seus piadecentores - tao do gosto dos maus políticos e administradores - poderemos Contar enfim, com uma "publicação viva, dinâmica. ..., instrumento capaz de servii î đilvulgaçđ̃o da cultura, à informação científica e aos interesses comerciais."

Istamos todos de parabéns por este lançamento da Biblioteca Nacional: a

I CALDEIRA, P. T. \& CARVALHO, M. L. B. de. O problema editorial da bibliografia brasileifi corrente, Revista Brastletra de Biblioteconomia e Documentação, São Paulo, 13(3/4) :210-6, jui / $/$ des. 1980
Diretora-Geral e escritora Maria Alice Barroso e toda a sua equipe de competentes profissionais, por uma realização que desejamos duradoura; nós todos - professores, bibliotecários, pesquisadores, editores, livreiros, cientistas, leitores os mais diversos - por mais este valioso instrumento de informação.

\section{BIBLIOGRAFIA CONSULTADA}

1 BIBLIOGRAFIA BRASILEIRA. Rio de Janeiro, v.1, n.1/2, 1983

2. CALDEIRA, P. T. \& CARVALHO, M. L. B. de. O problema editorial da bibliografia brasileira corrente. Revista Brasileira de Biblioteconomia e Documentação, São Paulo, 13(3/4):210-6, jul./dez. 1980.

3 FONSECA, Edson Nery da. Bibliografia Brasileira corrente: evolução e estado atual do problema. Ciência da Informação, Rio de Janéiro, I(1):12, 1972.

Endereço para correspondência: Coronel Genuíno, 433/504

90010 Porto Alegre, RS

Brasil. 